\title{
PENGARUH SUHU, WAKTU, DAN KONSENTRASI LARUTAN NATRIUM BIKARBONAT TERHADAP PENCUCIAN ISOEUGENYL ACETATE
}

\author{
Yeti Widyawati*, Muhammad Wahyudin, Lutfi Zakaria \\ Teknik Kimia, Fakultas Teknologi Industri, Universitas Jayabaya, Jakarta J1 Raya Bogor km 28 Cimanggis
}

Diterima 21 Januari 2018 / Disetujui 04 Februari 2019

\begin{abstract}
Isoeugenyl acetate is an eugenol derivative product in the form of white crystalline powder, it smells like vanilla, and has a spicy, hot and slightly sweet taste. Isoeugenyl acetate used in various industries, such as pharmaceuticals, cosmetics, food and beverages, cigarettes, pesticides, fishery, mining, packaging and other chemical industries. However, there is a problem in the product specification that is unacceptable to the consumer that is the acid number is high, it;s make of smell of acids in the product. Standart product of isoeugenyl acetate has an acid number of $0.5 \mathrm{mgKOH} / \mathrm{g}$. The research method used to decrease the acid number in isoeugenyl acetate is washing process. The aim of of this research are to obtain temperature, stirring time and the concentration of sodium bicarbonate. The condition of washing process of isoeugenyl acetate were obtained at temperature $35 \mathrm{oC}$, stirring time 100 minutes, and concentration sodium bicarbonate 3,5\%. In these conditions acid number of 0.4594 $\mathrm{mgKOH} / \mathrm{g}$ and the drying time of the isoeugenyl acetate product of 7 hours.
\end{abstract}

Keywords: Isoeugenyl acetate, sodium bicarbonate, Acid number

\begin{abstract}
ABSTRAK
Isoeugenyl acetate merupakan produk turunan eugenol yang berupa serbuk kristal berwarna putih, berbau creamy- spicy seperti vanilla, dan mempunyai rasa yang pedas, panas dan sedikit manis. Isoeugenyl acetate mempunyai peran yang strategis dalam berbagai industri seperti industri farmasi, kosmetika, makanan dan minuman, rokok, pestisida nabati, perikanan, pertambangan, kemasan dan industri kimia lainnya. Namun ada suatu permasalahan pada spesifikasi produk yang belum dapat diterima oleh konsumen yaitu tingginya kandungan angka asam pada produk akhir isoeugenyl asetat, hal ini menyebabkan bau asam pada produk tersebut sehingga mempengaruhi karakteristik produk secara organoleptik. Produk isoeugenyl asetat memiliki persyaratan kandungan angka asam sebesar 0,5 $\mathrm{mgKOH} / \mathrm{g}$. Metode penelitian yang digunakan untuk menurunkan angka asam pada produk akhir isoeugenyl asetat adalah melakukan pencucian dengan menyelidiki pengaruh suhu, waktu pengadukan dan konsentrasi larutan natrium bikarbonat yang digunakan dan pengaruh angka asam terhadap waktu pengeringan pada kristal isoeugenyl asetat. Hasil penelitian terhadap pengaruh suhu, waktu pengadukan dan konsentrasi larutan natrium bikarbonat yang digunakan didapat pada kondisi suhu $35^{\circ} \mathrm{C}$, waktu pengadukan 100 menit, dan konsentrasi larutan natrium bikarbonat 3,5\%. Dengan kondisi tersebut, produk isoeugenyl asetat yang dihasilkan memiliki angka asam sebesar 0,4594 $\mathrm{mgKOH} / \mathrm{g}$, sehingga waktu pengeringan terhadap produk isoeugenyl asetat adalah 7 jam.
\end{abstract}

Kata kunci : Kristal Isoeugenyl asetat, Larutan natrium bikarbonat, Angka asam

*Korespondensi Penulis:

Email : widya.w21@gmail.com 


\section{PENDAHULUAN}

Isoeugenyl acetate merupakan produk turunan eugenol yang berupa serbuk kristal berwarna putih, berbau creamy- spicy seperti vanilla, dan mempunyai rasa yang pedas, panas dan sedikit manis. Isoeugenyl acetate mempunyai peran yang strategis dalam berbagai industri (Ogata et al., 2000; Durville and Collet, 2001; Brechbill, 2005; Sumangat et al., 2005; Han, 2005 seperti industri farmasi, kosmetika, makanan dan minuman, rokok, pestisida nabati, perikanan, pertambangan, kemasan aktif dan industri kimia lainnya; Stanfill et al., 2006; Wiratno, 2009; Pramod et al., 2010).

Isoeugenyl acetate dibuat melalui reaksi asetilasi antara asam asetat anhidrat dengan isoeugenol menggunakan katalis padat acetilcat. Namun permasalahan yang dihadapi terhadap produk isoeugenyl acetate yang dihasilkan adalah mempunyai angka asam yang tinggi, yaitu sebesar $11 \mathrm{mgKOH} / \mathrm{g}$ dan memiliki aroma asam yang kuat. Sementara produk isoeugenyl acetate yang diinginkan konsumen harus sesuai standar SNI yaitu angka asam sebesar $0,5 \mathrm{mg} \mathrm{KOH} / \mathrm{g}$. Salah satu upaya yang dilakukan untuk menurunkan angka asam pada produk isoeugenyl acetate adalah dengan cara pencucian. Beberapa metode pencucian isoeugenyl acetate menggunakan metode pencucian dengan air dan $\mathrm{KOH}$. Proses pencucian isoeugenyl acetate menggunakan air memerlukan waktu selama 2 jam, dan produk isoeugenyl acetate masih mengandung angka asam yang tinggi yaitu sebesar $9 \mathrm{mgKOH} / \mathrm{g}$. Hal ini disebabkan karena air tidak dapat mengikat kandungan asam pada isoeugenyl acetate. Sementara metoda pencucian menggunakan larutan KOH $60 \%$ waktu yang diperlukaan 60 menit dan menghasilkan angka asam sebesar 0,4 $\mathrm{mgKOH} / \mathrm{g}$. Namun metode pencucian ini mengakibatkan produk isoeugenyl acetate terhidrolisis oleh $\mathrm{KOH}$ yang bersifat basa kuat, sehingga isoeugenyl acetate setelah mengalami proses pencucian selama satu jam berubah sifit fisiknya menjadi cair. Pada penelitian ini metode pencucian yang digunakan adalah menggunakan larutan natrium bikarbonat, karena natrium bikarbonat bersifat basa lemah sehingga proses hidrolisis terhadap kristal isoeugenyl acetate tidak terjadi. Tujuan penelitian ini adalah mendapatkan suhu, waktu pengadukan dan konsentrasi larutan natrium bikarbonat terbaik terhadap penurunan angka asam produk isoeugenyl acetate dan karakterisasi produk yang dihasilkan.

\section{METODE PENELITIAN}

\section{Bahan dan Alat}

Bahan baku yang digunakan pada penelitian ini adalah kristal isoeugenyl acetate dengan angka asam $11 \mathrm{mgKOH} / \mathrm{g}$, natrium bikarbonat, dan aquadest. Bahan untuk analisa yang digunakan adalah fenol, etanol dan toluena.

Peralatan yang digunakan pada penelitian ini adalah erlenmeyer, hot plate, magnetic stirrer, beaker glass, pipet tetes, corong pemisah. timbangan analitik, stopwatch, termometer, labu ukur, gelas ukur, fluidized bed dryer dan GC-MS

\section{Prosedur Percobaan}

Prosedur percobaan untuk proses pencucian isoeugenyl acetate adalah sebagai berikut : sebanyak 500 gram isoeugenyl acetate dengan angka asam $11 \mathrm{mg} \mathrm{KOH} / \mathrm{g}$ dan larutan natrium bikarbonat $1000 \mathrm{ml}$ dimasukkan kedalam wadah dengan perbandingan 1:2, kemudian dicampur dengan variabel suhu pemanasan $30-45^{\circ} \mathrm{C}$, waktu pengadukan 50-150 menit dan konsentrasi larutan natrium bikarbonat 1,5$3,5 \%$. Selanjutnya dilakukan proses sentrifugasi yaitu suatu proses pemisahan antara padatan dengan cairan dengan memanfatkan gaya sentrifugal, sehingga 
padatan akan tertahan didalam kain sentrifugal dan cairannya akan keluar melalui sisi celah sentrifuge, sehinga didapatkan kristal isoeugenyl acetate dalam keadaan semi basah. Kristal isoeugenyl acetate hasil dari sentrifugasi dalam keadaan semi basah, selanjutnya dilakukan proses pengeringan untuk mengurangi kandungan air pada kristal isoeugenyl acetate. Hal ini bertujuan untuk membangkitkan aroma pada kristal isoeugenyl acetate. Diagram alir penelitian proses pencucian isoeugenyl acetate dapat dilihat pada Gambar 1.

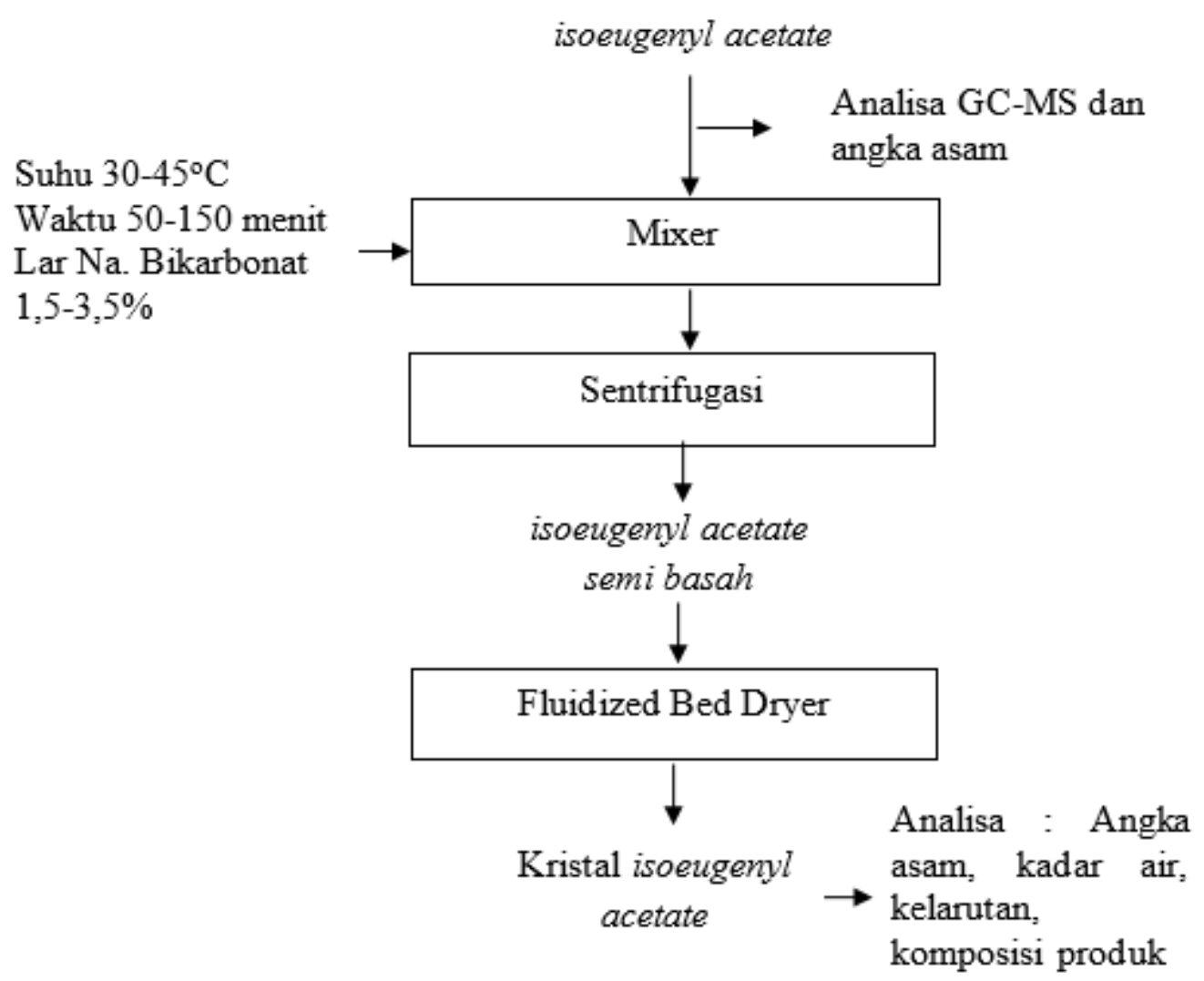

Gambar 1. Diagram alir proses pencucian kristal isoeugenyl acetate

\section{Analisa Angka Asam}

Sampel ditimbang sebanyak 10 gram dalam erlenmeyer $100 \mathrm{ml}$, larutkan dalam 50 ml larutan isopropanol dan toluen $1: 1$ yang telah dinetralkan dengan $\mathrm{KOH} 0,1 \mathrm{~N}$ dan indikator 5 - 6 tetes fenol. Pelarutan dilakukan dengan cara dipanaskan pelanpelan sambil dikocok. Selanjutnya menambahkan $0,8 \mathrm{ml}$ larutan fenol $0,1 \%$ dalam etanol. Sampel dititrasi dengan larutan $\mathrm{KOH} 0,1$ hingga terjadi perubahan warna kuning menjadi pink atau merah muda, lalu catat jumlah $\mathrm{KOH} 0,1 \mathrm{~N}$ yang diperlukan. Pemeriksaan ini diulang hingga 2 kali. Perhitungan angka asam sebagai berikut:

$$
\begin{aligned}
& \text { Angka asam }=\frac{(\mathrm{VxN}) \mathrm{KOH} \times 56,1}{(\mathrm{~m}) \text { Berat contoh }} \\
& \text { Dimana } 56,1=\text { Berat molekul } \mathrm{KOH} \\
& \mathrm{V}=\text { Volume larutan } \mathrm{KOH} \\
& \text { yang diperlukan (ml) } \\
& \mathrm{N}=\text { Normalitas } \mathrm{KOH} \\
& \mathrm{m}=\text { Berat contoh (gram) }
\end{aligned}
$$

\section{HASIL DAN PEMBAHASAN}

\section{Karakterisasi Bahan Baku}

Karaktersitik pendahuluan pada isoeugenyl acetate bertujuan untuk mengetahui komposisi sifat kimia isoeugenyl acetate. Karakteristik bahan baku ini 
dilakukan menggunakan Gas

Chromathography Mass Spectro (GC-MS).

isoeugenyl acetate sebelum proses

Gambar 2 memperlihatkan bahan baku

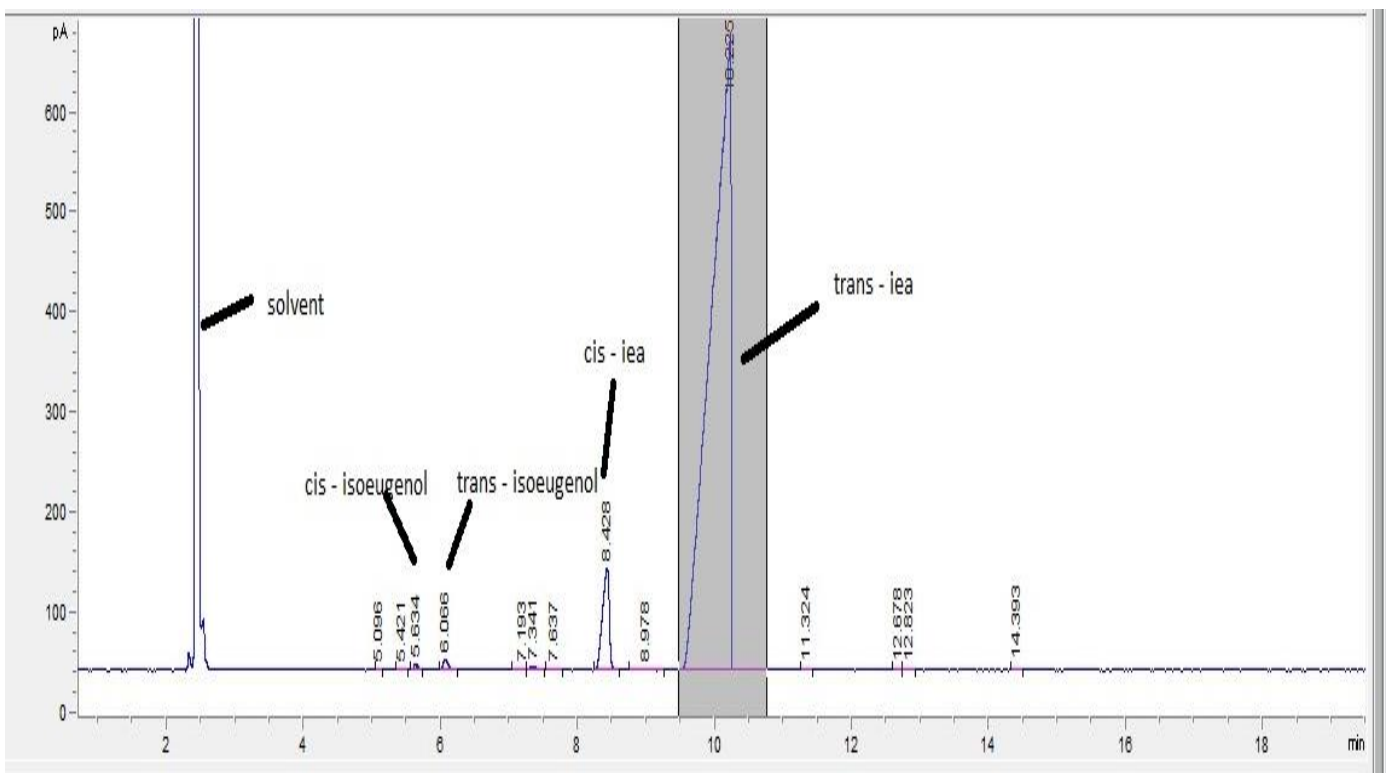

Gambar 2 Bahan baku kristal isoeugenyl asetat sebelum proses pencucian.

Gambar 2 memperlihatkan komposisi yang terdapat pada kristal isoeugenyl acetate sebelum proses pencucian, yaitu cis isoeugenol $0,16 \%$; trans isoeugenol $0,38 \%$; cis isoeugenyl acetate $5,22 \%$ dan trans isoeugenyl acetate $93,74 \%$. Sifat fisiko bahan baku isoeugenyl acetate sebelum proses pencucian dapat dilihat pada Tabel 1.

Tabel 1 Sifit fisik kristal isoeugenyl acetate sebelum proses pencucian.

\begin{tabular}{ll}
\hline Karakteristik & Hasil Pengujian \\
\hline Angka Asam & $11 \mathrm{mg} \mathrm{KOH} / \mathrm{g}$ \\
Kelarutan dalam etanol & $100 \%$ \\
Kadar Air & $0,05 \% \mathrm{~b} / \mathrm{b}$ \\
\hline
\end{tabular}

\section{Pengaruh Suhu Terhadap Angka Asam}

Proses pencucian kristal isoeugenyl acetate menggunakan natrium bikarbonat dengan perbandingan 1: 2 pada suhu $25^{\circ} \mathrm{C}$,
$35{ }^{\circ} \mathrm{C}, 45{ }^{\circ} \mathrm{C}, 55{ }^{\circ} \mathrm{C}, 65{ }^{\circ} \mathrm{C}$. Pengaruh suhu pencucian terhadap penurunan angka asam dapat dilihat pada Gambar 3.

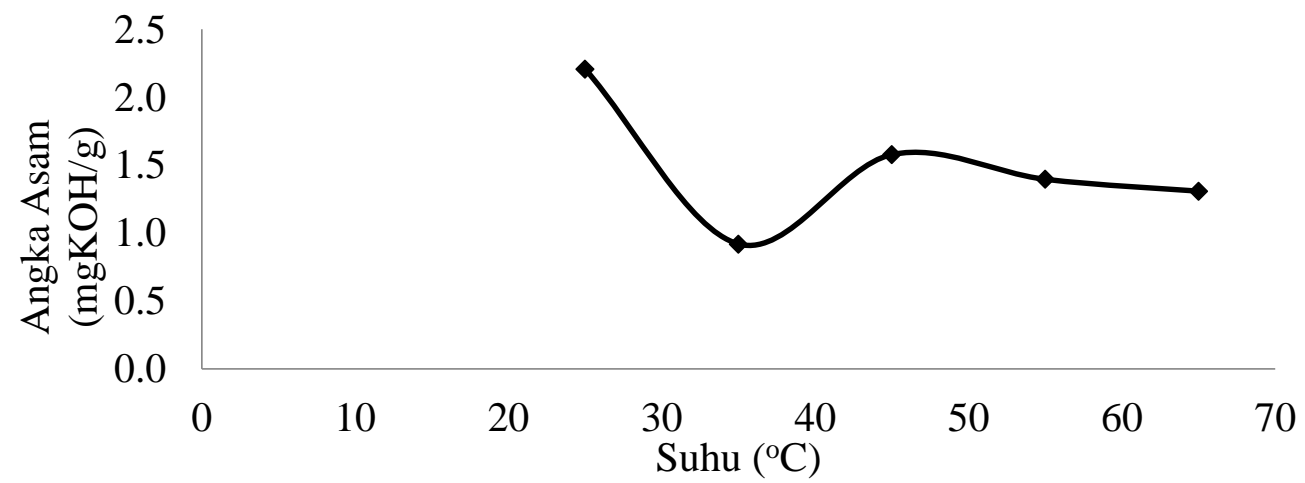

Gambar 3 Pengaruh suhu terhadap angka asam 
Gambar 3 memperlihatkan bahwa pada proses pencucian kristal isoeugenyl acetate pada suhu $25^{\circ} \mathrm{C}$, angka asam yang diperoleh sebesar 2,2069 mg KOH/g. Ketika pada suhu $35{ }^{\circ} \mathrm{C}$ diperoleh angka asam sebesar 0,9195 $\mathrm{mg} \mathrm{KOH} / \mathrm{g}$. Namun ketika suhu pencucian $45^{\circ} \mathrm{C}$ mengalami peningkatan angka asam sebesar 1,5769 mg KOH/g, hal ini disebabkan kristal isoeugenyl acetate memiliki titik leleh diatas suhu $45^{\circ} \mathrm{C}$, sehingga kristal isoeugenyl acetate menjadi larut dalam larutan pencuci. Kristal isoeugenyl acetate memiliki sifat kelarutan, larut dalam fixed oil, alkohol dan tidak larut dalam air.

\section{Pengaruh Waktu Pengadukan Terhadap Angka Asam}

Proses pencucian kristal isoeugenyl acetate menggunakan natrium bikarbonat dengan perbandingan 1: 2 pada waktu pengadukan 50, 75, 100, 125, dan 150 menit. Pengaruh waktu pengadukan terhadap penurunan angka asam dapat dilihat pada Gambar 4.

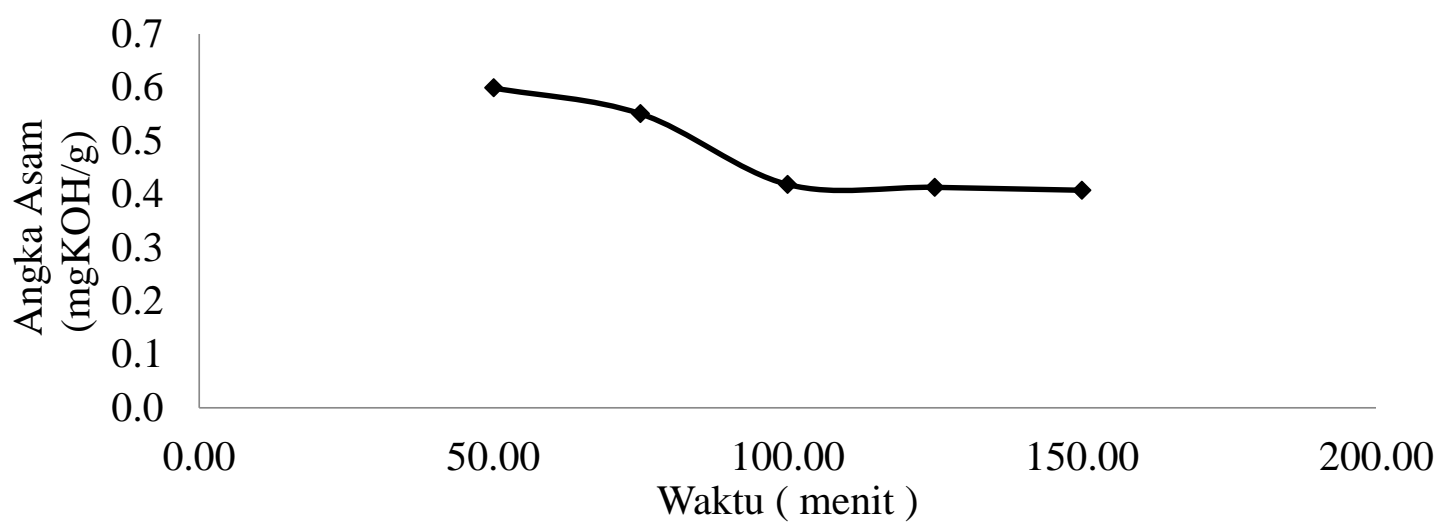

Gambar 4 Pengaruh waktu pengadukan terhadap angka asam

Gambar 4 memperlihatkan bahwa proses pencucian dengan waktu pengadukan selama 50 menit dan 75 menit diperoleh angka asam sebesar $0,5990 \mathrm{mg} \mathrm{KOH} / \mathrm{g}$ dan $0,5506 \mathrm{mg} \mathrm{KOH} / \mathrm{g}$. Namun ketika waktu pengadukan 100 menit diperoleh penurunan angka asam sebesar 0,4185 $\mathrm{mg} \mathrm{KOH} / \mathrm{g}$, hal ini di sebabkan luas kontak permukaan antara kristal isoeugenyl acetate dengan larutan pencuci semakin luas, dan ketika waktu pengadukan dinaikkan menjadi 125 menit dan 150 menit terjadi penurunan angka asam, namun tidak terlalu signifikan.

\section{Pengaruh Konsentrasi Larutan Natrium BiKarbonat Terhadap Angka Asam}

Proses pencucian kristal isoeugenyl acetate menggunakan natrium bikarbonat dengan konsentrasi 1,5-3,5 \%. Pengaruh konsentrasi natrium bikarbonat terhadap penurunan angka asam dapat dilihat pada Gambar 5.

Gambar 5 memperlihatkan bahwa pada konsentrasi larutan natrium bikarbonat $2 \%$ diperoleh angka asam sebesar 1,6527 $\mathrm{mgKOH} / \mathrm{g}$. Pada konsentrasi larutan natrium karbonat 2,5\% dan $3 \%$ diperoleh angka asam sebesar 1,5815 mg KOH/g dan 0,998 $\mathrm{mg} \mathrm{KOH} / \mathrm{g}$. Namun ketika konsentrasi larutan natrium bikarbonat 3,5\%, angka asam mengalami penurunan sebesar $0,4910 \mathrm{mg}$ $\mathrm{KOH} / \mathrm{g}$. Hal ini disebabkan karena semakin tinggi konsentrasi larutan natrium bikarbonat, maka angka asam turun. Hal ini disebakan karena sifat larutan pencuci dari natrium bikarbonat bersifat basa. Semakin besar konsentrasi larutan natrium bikarbonat semakin turun angka asam pada produk isoeugenyl acetate namun tidak signifikan. 


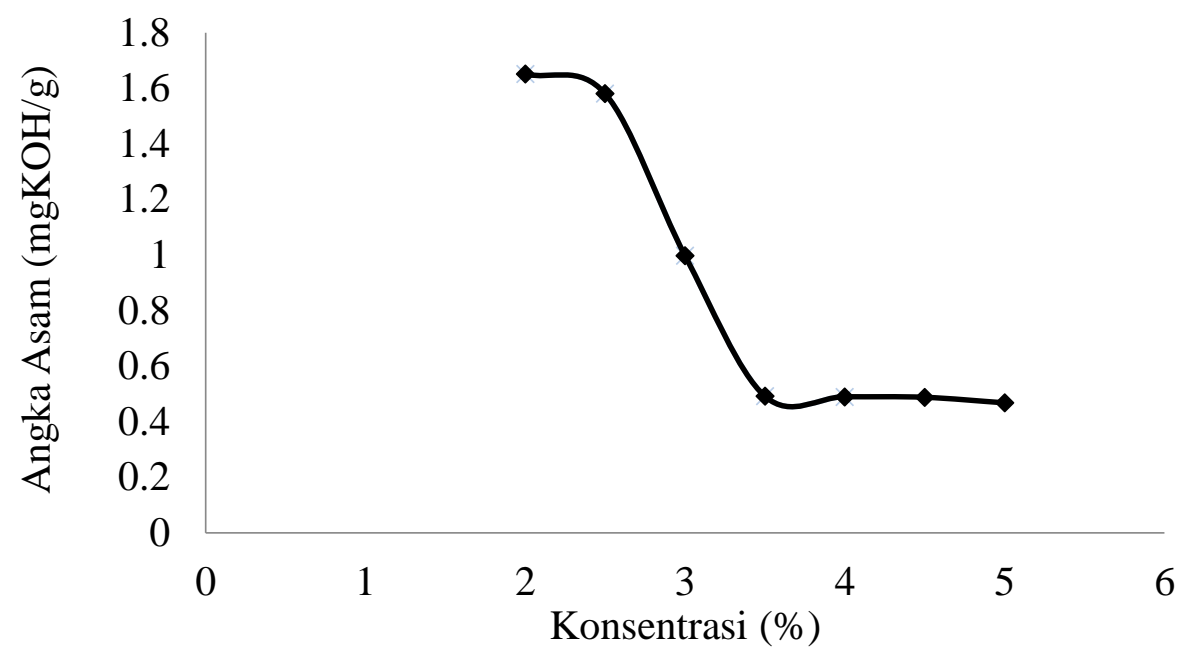

Gambar 5 Pengaruh konsentrasi larutan natrium bikarbonat terhadap angka asam

Pengaruh Angka Asam Terhadap Waktu Pengeringan

Proses pengeringan produk kristal isoeugenyl acetate menggunakan alat Fluidized Bed Dryer (FBD). Proses ini berlangsung setelah proses pencucian kristal isoeugenyl acetate dengan larutan natrium bikarbonat, hal ini dilakukan karena kristal isoeugenyl asetat yang dihasilkan pada proses sebelumnya masih memiliki kandungan air yang cukup banyak, selain itu bertujuan untuk menguapkan pelarut yang masih terkandung dalam kristal tersebut sehingga aroma dan warna kristal isoeugenyl acetate sesuai dengan spesifikasinya, yaitu berbau spicy dan berwarna putih. Pengaruh angka asam kristal isoeugenyl acetate terhadap waktu pengeringan dilihat pada Gambar 6.

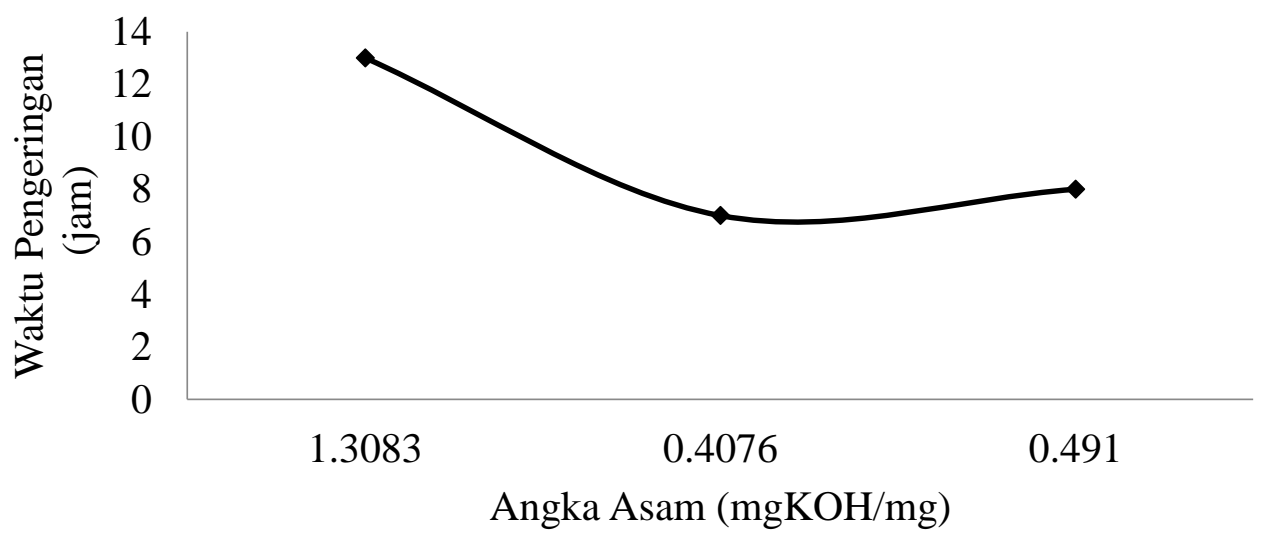

Gambar 6 Pengaruh angka asam terhadap waktu pengeringan

Gambar 6 memperlihatkan bahwa pengaruh angka asam terhadap lama pengeringan sangat siginfikan. Kristal isoeugenyl acetate yang memiliki angka asam $0,4910 \quad \mathrm{mg} \quad \mathrm{KOH} / \mathrm{g}$ waktu pengeringannya selama 8 jam, dan kristal isoeugenyl acetate yang memiliki angka asam $0,4076 \quad \mathrm{mg} \quad \mathrm{KOH} / \mathrm{g}$ waktu pengeringannya menjadi 7 jam, namun pada kristal isoeugenyl acetate yang memiliki angka asam $1,3083 \mathrm{mg} \mathrm{KOH} / \mathrm{g}$ waktu pengeringan yang dibutuhkan sebesar 13 jam. Semakin besar angka asam kristal isoeugenyl acetate semakin lama waktu yang diperlukan untuk proses pengeringan. Hal ini diakibatkan karena semakin tinggi angka 
asamnya semakin banyak zat lain yang harus diuapkan pada proses pengeringan sehingga zat-zat tersebut tidak mencemari dari kandungan, warna dan aroma khas kristal isoeugenyl acetate.

\section{Karakteristik Produk Kristal Isoeugenyl}

Tabel 2 Sifat Fisiko Kimia Kristal Isoeugenyl Acetate.

\begin{tabular}{ll}
\hline Parameter & Hasil Pengujian \\
\hline Kenampakan & Kristal putih \\
Angka Asam $(\mathrm{mg} \mathrm{KOH} / \mathrm{g})$ & 0,4594 \\
Kadar Air $(\%)$ & 0,01 \\
Kelarutan dalam etanol $(\%)$ & 100 \\
cis isoeugenol & $0,15 \%$ \\
trans isoeugenol & $0,31 \%$ \\
cis isoeugenyl acetate & $4,90 \%$ \\
trans isoeugenyl acetate & $94,30 \%$ \\
\hline
\end{tabular}

\section{KESIMPULAN}

\section{Kesimpulan}

Produk isoeugenyl acetate memiliki angka asam sebesar 0,4594 $\mathrm{mg} \mathrm{KOH} / \mathrm{g}$ pada kondisi operasi suhu pencucian $35^{\circ} \mathrm{C}$, waktu pengadukan 100 menit dan konsentrasi larutan natrium bikarbonat 3,5\% dengan lama pengeringan selama $7 \mathrm{jam}$.

\section{DAFTAR PUSTAKA}

Brechbill, G.O. 2005. A Reference Book on Fragrance Ingredients. http://www.perfumerbook.com

Durville, P. and A. Collet. 2001. Clove oil used as an anaesthetic with juvenile tropical marine fish. SPC Live Reef Fish Information Bulletin 9 : 17-19.

Han, J.H. 2005. New Technologies in Food Packaging : Overview. In : Innovations in Food Packaging, Han, J.H. (Ed.). Elsevier Academ

Ogata, M., M. Hoshi, S. Mangala and T. Endo. 2000. Antioxidant activity of eugenol and related monomeric and

\section{Acetate}

Karakteristik sifat fisiko kimia produk kristal isoeugenyl acetate pada kondisi operasi proses suhu $35^{\circ} \mathrm{C}$, waktu pengadukan 100 menit dan konsentrasi larutan natrium bikarbonat 3,5\%, dapat dilihat pada Tabel 2 . $94,30 \%$

dimeric compounds. Chem. Pharm. Bull. 48(10) : 1467-1469.

Pramod, K., S.H. Ansari and J. Ali. 2010. Eugenol: a natural compound with versatile pharmacological actions. Natural Product Communications 5(12) : 1999-2006

Sumangat, D., M. P. Laksmanahardja, Hernani, N. Nurjannah, dan Mamun. 2005. Penelitian pengolahan isoeugenol dari minyak daun cengkeh. Buletin Teknologi Pascapanen Pertanian Volume 1(1). http://www.pascapanen.litbang.deptan. go. id. (26 April 2011).

Stanfill, S.B., C.R. Brown, X.J. Yan, C.H. Watson and D.L. Ashley. 2006. Quantification of flavor-related compounds in the unburned contents of bidi and clove cigarettes. Journal of Agricultural and Food Chemistry 54 : 8580-8588

Wiratno. 2009. Cengkih berpotensi sebagai pestisida nabati. Warta Penelitian dan Pengembangan Pertanian 31(6) : 5-7. 